\title{
MEIO AMBIENTE, ESCOLA E A FORMAÇÃO DOS PROFESSORES
}

\author{
Environment, School and teachers education
}

\author{
André Loureiro Chaves \\ Maria Eloisa Farias ${ }^{2}$
}

\begin{abstract}
Resumo: A idéia de Meio Ambiente será a mesma na mente dos diferentes professores? Junto à indagação do que estes professores compreendem por situação de aprendizagem, tem-se as duas questóes centrais da pesquisa. Dependendo das respostas que são dadas, diferentes projetos de Educação Ambiental (EA) são implementados. A busca de informações deu-se através da aplicação de questionário junto a professores do Ensino Fundamental (5. a a 8. a séries) de escolas nos municípios de Estância Velha e Canoas, totalizando 36 docentes. Os dados coletados indicaram um predomínio da visão antropocêntrica, que privilegia a utilidade dos recursos naturais para a sobrevivência do homem. Em relação aos tipos de atividades desenvolvidas, constatou-se, primeiro, que a periodicidade dos trabalhos, em sua grande maioria, são de curto prazo; alguns têm a duração anual. Quanto à amplitude e composição das experiências, envolvem atividades pontuais e de caráter comemorativo. Constatou-se, também, que são trabalhos desarticulados, identificando-se mais de um tema de estudo através de diversas estratégias. Ou seja, desenvolve-se várias ações sem um vínculo temático ou metodológico. Um conjunto de açōes, desenvolvido processualmente, a partir de um eixo temático-metodológico, representaria um salto qualitativo.
\end{abstract}

Unitermos: educação ambiental; formação de professores; Ensino Fundamental

Abstract: Will the idea of environment be the same in the minds of different teachers? Along with inquiry into whatthat these teachers understand by the situation of learning, there are two main research questionsof the research. Depending on the answers that are given, different projects inof environmental education (EE) are implemented. The search of information was givendata for the research presented here was collected by the application of questionnaires toalong with the teachers of Secondary School (5th to 8th grade) at schools in Estância Velha and Canoas adding up to 36 teachingers staff. The data collected indicated a predominance of anthropocentric vision that prevails in utilities of sees natural resources in terms of to the survival of mankind. In relation to the kinds of the developed activities developed, it was is possible torealized, first of all, that the length periodicity of theresearch projectses is usually short; some of them have annual duration. Concerning About the amplitude and composition of the experiences, the research projects involved punctual activities of a commemorative nature. It was also realized that these are disjointed researches; in which we can identify more than one subject of study, through many strategies. This means that many actions are developed, without a methodological or thematic bond. A group of actions, developed in a processual way, from a thematic axis would provide a qualitative improvement.

Keywords: environmental education; formation of teachers; Basic Education

\section{Introdução: bases fudamentais da educação ambiental}

A humanidade é parte da natureza e depende dela para sua sobrevivência, mas a civilização, ou o conjunto de caracteres próprios da vida social, política, econômica e cultural da humanidade, proporciona a ela o poder de intervir alterando a natureza em escala sempre crescente, para melhor ou para pior. Segundo VIOLA (1987), entre os efeitos negativos desta intervenção humana encontram-se: ameaça à vida biológica nos oceanos, lagos e rios, devido à poluição de

\footnotetext{
${ }^{1}$ Professor-pesquisador vinculado ao Curso de Engenharia Ambiental e ao PPGEAM - Programa de Pós-Graduação em Engenharia: Energia, Ambiente e Materiais/Ulbra.E-mail: andreplc@terra.com.br

${ }^{2}$ Professora-pesquisadora vinculada ao Curso de Biologia e ao PPGECIM - Programa de Pós-Graduação em Ensino de Ciências e Matemática/Ulbra.E-mail:mariefs@ulbra.br
} 
suas águas; envenenamento da atmosfera com vapores prejudiciais; destruição do solo através de uso indevido provocando erosões, inundaçôes e alterações do clima.

Para avaliar a extensão dos danos ecológicos é preciso estudar os males causados ao meio ambiente. O comportamento humano tem gerado múltiplos e profundos agravos ecológicos ao longo da história. Dos períodos de civilização da Antigüidade e da Idade Média, podem-se extrair informações que representam importantes contribuições aos estudos atuais (LIEBMANN, 1976). Foi ao abandonar as regiōes habitadas, em busca de novas terras, que o homem da Antigüidade ignorou as conseqüências dos danos ao meio ambiente por ele próprio provocados. O comportamento predatório não é recente na história da humanidade.

Para o homem moderno, as migrações diminuem e são acompanhadas da necessidade de uma reorientação de valores, talvez uma "nova renascença”, face às necessidades de modificações nos processos industriais, da aceitação do que HABERMAS (1990) denomina de "soberania popular como procedimento" e de um ordenamento jurídico da questão ambiental.

Atualmente, é conhecida a ubiqüidade dos problemas ambientais: o de ocorrer ao mesmo tempo e, praticamente, em todos os lugares. A ocorrência, portanto, dos agravos ao meio ambiente $e$ saúde causados em escala global oferece uma possibilidade de compreender o surgimento da "consciência ecológica" nas três últimas décadas (marcadamente durante a década de 1980) e de compreender o deslocamento da questão ambiental até então circunscrita a alguns espaços (universidades, entidades ambientalistas, associações de denúncia da degradação ambiental) para o cotidiano da população, mediante os meios de comunicação, os movimentos sociais e discussões de caráter político.

A problemática ambiental transformou-se num dos mais sérios desafios que a humanidade tem de enfrentar a curto prazo. A consciência ecológica não nasce no vazio. Ela emerge, antes de tudo, de uma realidade: a poluição, a fome, as desigualdades sociais, a interferência do sistema econômico no sistema ecológico, a deterioração da qualidade de vida, a degradação do meio ambiente, a ocupação desordenada do espaço ambiental.

Também, a consciência ecológica emerge, igualmente, no contexto de uma nova consciência ética (MOSER, 1984). Entretanto, os problemas ambientais não encontram seu entendimento, simplesmente, a partir de uma perspectiva ética. Os problemas ecológicos somente serão equacionados na medida em que se levar em conta todos os determinantes e aspectos deste processo.

É inquestionável, hoje em dia, a importância da tecnologia não só para o conforto e bem-estar. Mas para a própria sobrevivência da humanidade. Contudo, inicia-se a compreender um equívoco. Esta capacidade de atuar sobre o meio ambiente, modificando-o (conseqüência direta dos avanços tecnológicos), deu ao homem uma sensação de "superioridade" em relação à natureza. Sensação que só é verdadeira (se puder se colocar nestes termos) numa perspectiva de curto prazo. A longo prazo o homem necessitará voltar a se submeter às "leis gerais da biosfera" (COIMBRA, 2002).

A garantia de um futuro depende, portanto, de uma reflexão sobre o comportamento humano diante dos recursos naturais. Uma revisão que é, em parte, tecnológica e, em grande parte, ética. É preciso buscar formas de compatibilizar o desenvolvimento tecnológico com a qualidade do meio ambiente. Este é o ponto de partida para se traçar uma unidade de propósitos e os limites da Educacão Ambiental.

\section{Concepção da pesquisa}

\section{Contexto que a justificou}

A literatura mostra pesquisas que evidenciam uma inquietante contradição: a constatação inequívoca, por um lado, de que existe uma "consciência do problema ambiental". Por 
outro lado, no entanto, ela permanece limitada ao plano abstrato e mais relacionada com dilemas distantes do cotidiano. As pessoas afirmam, nestes estudos, não ter alterado em nada o seu comportamento em consideração ao Meio Ambiente (CHAVES, 1993).

No estado atual da questão ambiental, mostra-se ainda útil retomar o problema do que se entende por Educação Ambiental e como ela vem sendo desenvolvida nas escolas. Não se tem tanta certeza de que seja tão unânime a importância dada, pela escola, à Educação Ambiental. Perguntando-se de outra forma: por que a temática ambiental seria um valor para a educação? Qual seria este lugar da temática ambiental na educação? (CARVALHO, 1989; FRACALANZA, 1992).

Entretanto, para se realizar uma pesquisa que pudesse ter alguma utilidade, foi preciso limitá-la. Foi sobre a análise do que se entende por meio ambiente, problemática ambiental, situaçōes de aprendizagem e educação ambiental que a pesquisa, inicialmente, concentrou-se; estudando a compreensão de professores acerca destes temas. O que faz e o que pensa o professor em relação à Educação Ambiental? Qual a relação que haveria entre a compreensão que tem da problemática ambiental e o que faz?

A forma como o indivíduo posiciona-se acerca destes temas, e o professor de modo particular, determinam o tipo de programa educacional ligado à temática ambiental que será desenvolvido. Por exemplo, as propostas serão bem simplificadas se o quadro de interpretação for "a degradação ambiental está em função do aumento populacional". Dificilmente haverá outro programa que não seja um controle da população (CARVALHO, 1989).

\section{Objetivos}

- Conhecer atitudes, juízos e informações que o professor tem em relação à problemática ambiental.

- Identificar concepções pedagógicas que subjazem à prática de Educação Ambiental deste professor.

- Produzir subsídios para a organização e o desenvolvimento de Curso de Formação de Professores na área da Educação Ambiental.

\section{Metodologia}

\section{Sobre o universo de pesquisa}

A busca de informaçōes deu-se junto a professores do Ensino Fundamental (5.a a 8.a série) de escolas nos municípios de Estância Velha e Canoas, totalizando 36 docentes.

Quanto à Cidade de Estância Velha, para o universo de professores pesquisados, aproveitou-se o evento "Curso de Reciclagem em Ciências", organizado pela Universidade Luterana do Brasil (Ulbra) e ministrado pela Professora Maria Eloisa Farias. Reuniu num mesmo local durante um final de semana, 25 professores vindos de diferentes escolas do município. $\mathrm{O}$ instrumento foi respondido durante intervalo das atividades que estavam sendo desenvolvidas.

Quanto ao universo de professores da Cidade de Canoas, trabalhou-se com 3 escolas: Irmão Pedro (Escola Municipal), Gomes Jardim (Escola Estadual) e Cristo Redentor (Escola Particular). Aqui, o procedimento foi distinto. Iniciou-se com uma visita à Direção das Escolas para apresentação do projeto da pesquisa. Em visita de retorno, deixou-se os instrumentos, recolhendo-os posteriormente. Houve baixo retorno dos questionários. O instrumento foi considerado longo demais pelos professores. Outra hipótese seria a de que, por se sentirem avaliados, teriam apresentado dificuldade na elaboração dos conceitos. 
Sobre os procedimentos e instrumentos de pesquisa

Uso do procedimento metodológico da triangulação, com a obtenção de dados através de:

- aplicação de questionário;

- aplicação informal da técnica do Grupo Focal (WESTPHAL, BÓGUS, FARIA, 1996);

- observação da prática dos professores.

\section{Resultados e discussão}

\section{Quanto à noção de Meio Ambiente}

A idéia de meio ambiente não é a mesma na mente das diferentes pessoas. Basta tentar-se uma definição. Quando se pensa em meio ambiente, imagina-se, por exemplo, coisas ou interaçôes? Ou coisas interagindo? Ou realiza um juízo de valor? A imagem refere-se a elementos inanimados ou contém seres vivos? Refere-se apenas a elementos naturais ou contém elementos artificiais? A sociedade humana está presente? É uma visão paradisíaca ou conflituosa? (COIMBRA, 2002).

Pode-se, conforme Reigota (1995), classificar essas representaçôes simbólicas associadas à noção de meio ambiente em três tipos:

- naturalista: que se caracteriza por evidenciar somente os aspectos naturais do ambiente; - antropocêntrica: privilegia a utilidade dos recursos naturais para a sobrevivência do homem;

- globalizante: evidencia as relações recíprocas entre natureza e sociedade.

Os dados coletados apontaram um predomínio, entre os professores, da visão antropocêntrica $(62,9 \%)$, seguida pela visão naturalista $(25,7 \%)$ e globalizante $(11,4 \%)$ (Gráfico 1).

Gráfico 1: O que o meio ambiente representa para você?

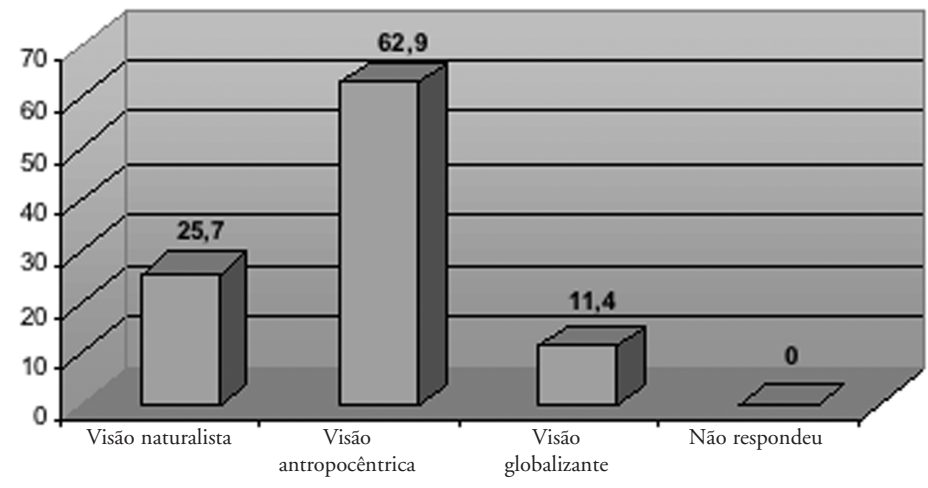

$$
\mid
$$

O que se percebe é a necessidade de buscar um conceito que atenda à essência e amplitude do que se compreende por meio ambiente contemporaneamente.

\section{Quanto à Educação Ambiental e à preparação do professor}

Sobre a Educação Ambiental, afirmaram não ser esta uma disciplina a cargo de um professor, mas um programa que integre as várias disciplinas e a escola como um todo. Por outro lado, $77,8 \%$ queixam-se que, com a atual formação, não estariam preparados para esta atuação interdisciplinar (Gráfico 2). 


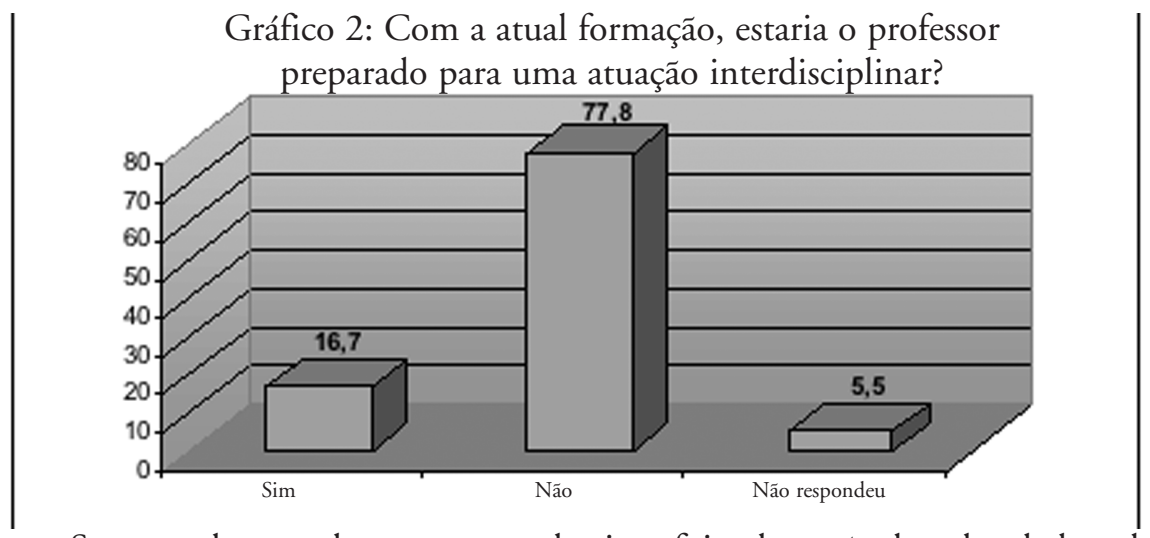

Surpreendente, sob certo ponto de vista, foi a detecção do valor dado pelo professor à experiência com a pesquisa. Dos participantes, 97,2\% pensam ser importante que o professor desenvolva atividade de pesquisa para poder melhor trabalhar interdisciplinarmente (Gráfico 3). A pesquisa, como lugar privilegiado para a compreensão da natureza interdisciplinar do conhecimento humano, prepara-os, portanto, para atuarem nesta perspectiva.

O professor tem uma compreensão crítica da educação e da Educação Ambiental; contudo, as situaçôes de aprendizagem relacionadas com a temática ambiental acabam, muitas vezes, mantendo suas bases fixadas no modelo tradicional de educação.

Gráfico 3: Você acha importante que o professor desenvolva atividade de pesquisa para poder melhor atuar interdisciplinarmente?

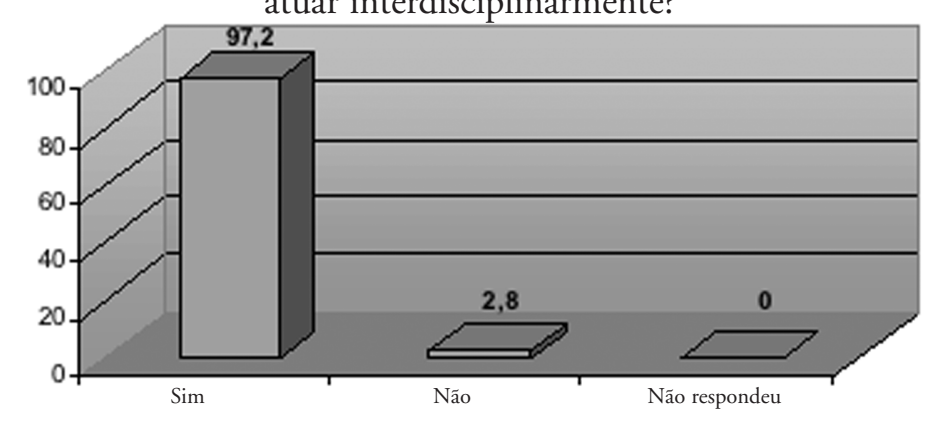

A meta mínima dos professores, em especial dos de Ciências, quando tratam de meio ambiente com seus alunos no Ensino Fundamental, é a de fornecer a eles oportunidades para que construam os conceitos próprios das Ciências Naturais, que são necessários ao entendimento dos assuntos ambientais. $\mathrm{Na} 5$. $^{\mathrm{a}}$ série, o ambiente: água, ar e solo, nesta divisão tradicional; na 6. a série, seres vivos; na 7. a série, corpo humano; na 8. a série, Química e Física (MOISÉS, 1995).

Entretanto, ainda segundo Moisés (1995), seria possível pensar-se na ampliação desta meta. Admitir a possibilidade de concebê-los como alunos prontos a serem desafiados a aprender conceitos relativos a desenvolvimento econômico (socialmente justo), sustentabilidade ecológica e participação social (democrática). 


\section{Quanto às atividades desenvolvidas}

Em relação aos tipos de atividades desenvolvidas, quando da realização dos projetos de Educação Ambiental, constatou-se, primeiro, que a periodicidade dos trabalhos, em sua grande maioria, são de curto prazo; apenas alguns têm a duração anual. Quanto à amplitude e composiçãao das experiências, como se observa no Gráfico 4, 17,3\% dos projetos envolveram a escola como um todo e $28,9 \%$ realizaram-se abarcando a comunidade da área de abrangência da escola; entretanto, em atividades pontuais e de caráter comemorativo, confirmando pesquisas realizadas por Sansolo e Manzochi (1995).

Gráfico 4: Quando da realização dos projetos de Educação Ambiental desenvolvidos com os alunos, eles envolveram

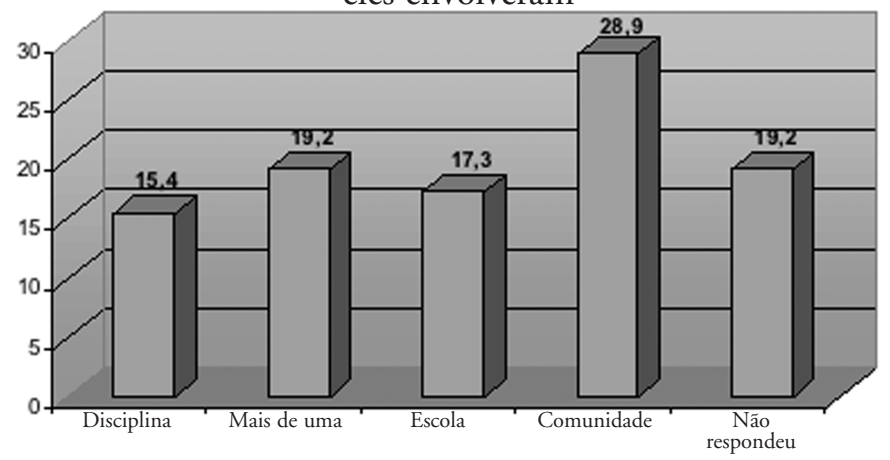

Observou-se, também, que são trabalhos desarticulados, identificando-se mais de um tema de estudo, através de diversas estratégias. Numa das escolas pesquisadas, o trabalho com os alunos da $5^{a}$ série envolvia plantio de horta, palestras sobre o efeito estufa ou a deterioração da camada de Ozônio e excursão ao Zoológico ou a alguma Unidade de Conservação. Isto é, desenvolviam-se várias açôes, sem um vínculo temático ou metodológico. Um conjunto de açôes, desenvolvido processualmente, a partir de um eixo temático-metodológico, representaria um salto qualitativo (SANSOLO e MANZOCHI, 1995).

Conforme Gráfico 5, quando questionados sobre as dificuldades para a realização de Projetos de Educação Ambiental, chama a atenção, por um lado, a falta de troca de experiências com outros professores que buscam desenvolver o mesmo tipo de trabalho (19,5\%) e, por outro lado, aqueles colegas que desaprovam ou não acreditam nas caraterísticas de uma atividade desta natureza $(19,5 \%)$. As condição de trabalho $(25 \%)$ e os recursos didáticos disponíveis (25\%) também são apontados. A condições de vida dos alunos é indicada como outra importante dificuldade $(22,2 \%)$. Além da própria formação, já destacada.

Gráfico 5: Dificuldades encontradas para a realização de projetos em Educação Ambiental

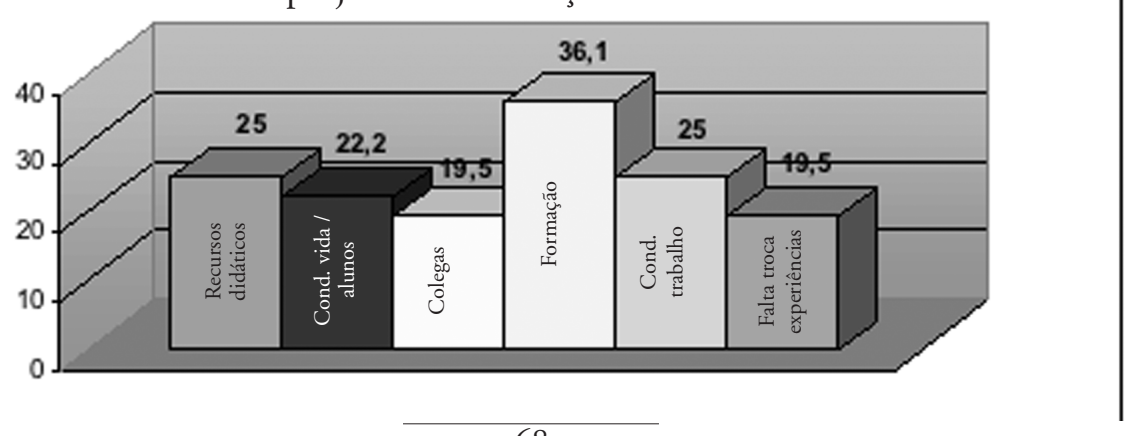




\section{Quanto à dimensão politica da Educação Ambiental}

Outro aspecto positivo que chamou a atenção foi o número de projetos que envolveram a participação de outras instituições ou organizações (Gráfico 6).

Gráfico 6: Nestes projetos de Educação Ambiental dos quais você participou, houve a colaboração de alguma instituiçãa?

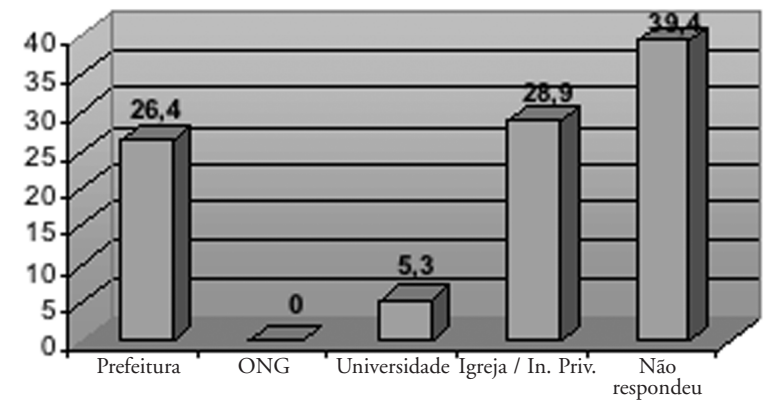

É relevante perceber, cotejando-se as informaçōes do Gráfico 4 (Comunidade: 28,9\%) e Gráfico 7 (Igreja, Iniciativa Privada: 28,9\%), o que se pode supor como o sentido dado à noção de comunidade, por parte dos professores. Os Projetos de Educação Ambiental que tiveram o seu desenvolvimento vinculado à comunidade são aqueles que, aqui, estão associados à Igreja e à Iniciativa Privada. As Prefeituras de Estância Velha e Canoas e Universidades não fariam parte, segundo esses professores, desta "Comunidade".

Por outro lado, a atuação, segundo a maioria dos professores $(52,8 \%)$, estaria sustentada pela percepção de que a proteção ao meio ambiente deve ser uma questão assumida pela sociedade como um todo (Gráfico 7).

Gráfico 7: A preocupação com o meio ambiente deveria ser uma questão

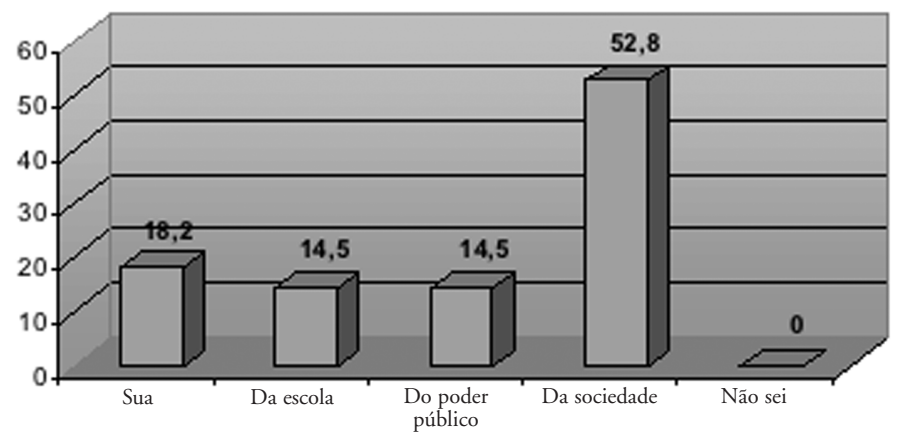

Medidas governamentais isoladas, ou de organizações não-governamentais, terão pequeno efeito quando não forem apoiadas e compreendidas pela população. Tal compreensão e participação depende da educação da qual deve fazer parte a informação, a análise e a discussão das questôes que afetam o meio ambiente (KRASILCHIK, 1986). Sendo, para isto, necessário um professor que se sinta com uma formação que o deixe preparado para esta atuação.

Portanto, significa pensar na preparação do professor para este desempenho. Estimulando-o a trabalhar de forma articulada, envolvendo outras instituições e organizaçōes e ampliando sua meta quando trata do meio ambiente com seus alunos, desafiando-os a aprender conceitos relativos ao desenvolvimento sustentável. 


\section{Conclusões}

O professor tem uma compreensão crítica da educação e da Educação Ambiental; contudo, as situaçōes de aprendizagem relacionadas com a temática ambiental acabam, ainda, muitas vezes, mantendo suas bases fixadas no modelo tradicional de educação.

Os professores queixam-se que, com a atual formação, não estariam preparados para uma atuação interdisciplinar, postura inerente aos Projetos de Educação Ambiental. Apontam para a importância, valorizando-a, da atividade de pesquisa para poderem melhor trabalhar interdisciplinarmente e para a necessidade do envolvimento com outras instituiçôes, mesmo que os projetos até então implementados, em parte, tenham obtido esta amplitude.

Os chamados Projetos de Educação Ambiental, com trabalhos de maior duração (mínimo anual) e certa integração entre si, envolvendo outras organizações, garantindo esta qualidade de penetração propiciada pelo tempo e pelo planejamento, que os diferencia daquelas outras atividades pontuais ou desarticuladas, não foram detectados.

Pretende-se, com esse artigo, indicar a necessidade de romper as barreiras que dificultam reflexões mais contundentes sobre os temas que dizem respeito ao meio ambiente e traçar, a respeito da Educação Ambiental, seus princípios, papel e limites.

\section{Referências}

CARVALHO, L. M. A temática ambiental e a escola de primeiro grau. 1989. 286 p. Tese

(Doutorado em Educação) - Faculdade de Educação, Universidade de São Paulo, São Paulo, 1989.

CHAVES, A. P. L. Temática ambiental: instituiçōes envolvidas e a imprensa na Cidade de São Paulo. 1993. 142 p. Dissertação (Mestrado em Saúde Pública) - Faculdade de Saúde Pública, Universidade de São Paulo, São Paulo, 1993.

COIMBRA, J. A. A. O outro lado do meio ambiente. São Paulo: Millennium, 2002.

FRACALANZA, D. C. Crise ambiental e ensino de ecologia: o conflito na relação homem-mundo natural. 314 p. 1992. Tese (Doutorado em Educação) - Faculdade de Educação, Universidade Estadual de Campinas, Campinas, 1992.

HABERMAS, J. Soberania popular como procedimento: um conceito normativo do espaço público. Novos Estudos Cebrap, São Paulo, v. 26, p. 100-113, 1990.

KRASILCHIK, M. Educação ambiental na escola brasileira: passado, presente e futuro. Ciência e Cultura, São Paulo, v. 38, n. 12, p. 1958-1961, 1986.

LIEBMANN, H. Terra, um planeta inabitável: da antigüidade até os nossos dias, toda a trajetória poluidora da humanidade. São Paulo: Melhoramentos, 1976.

MOISÉS, H. N. O meio ambiente no ensino de ciências. In: SORRENTINO, M.; TRAJBER, R.; BRAGA, T. (Org.). Cadernos do III Fórum de Educação Ambiental. São Paulo: Gaia, 1995.

MOSER, A. O problema ecológico e suas implicações éticas. Petrópolis: Vozes, 1984. 
REIGOTA, M. Meio ambiente e representação social. São Paulo: Cortez, 1995. (Questôes da nossa época, 41).

SANSOLO, D. G.; MANZOCHI, L. H. Educação, escola e o meio ambiente. In: SORRENTINO, M.; TRAJBER, R.; BRAGA, T. (Org.). Cadernos do III Fórum de Educação Ambiental. São Paulo: Gaia, 1995.

VIOLA, E. O movimento ecológico no Brasil (1974-1986): do ambientalismo à ecopolítica. In: PÁDUA, J. A. (Org.). Ecologia e política no Brasil. Rio de Janeiro: Espaço e Tempo/IUPERJ, 1987.

WESTPHAL, M. F., BÓGUS, C. M., FARIA, M. M. Grupo Focal - experiências precursoras do uso da técnica em programas educativos em saúde no Brasil. Boletin de la Oficina Sanitaria Panamericana, Washington, v. 120, n. 4, p. 472-482, 1996. 